\title{
Correction to: Simulation and Estimation of Future Precipitation Changes in Arid Regions: a Case Study of Xinjiang, Northwest China
}

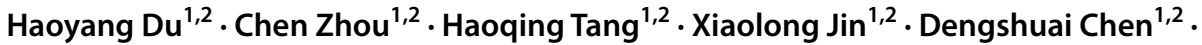
Penghui Jiang ${ }^{1,2} \cdot$ Manchun $\mathrm{Li}^{1,2}$

Published online: 1 November 2021

(c) Springer Nature B.V. 2021

Correction to: Climatic Change (2021) 167:43

https://doi.org/10.1007/s10584-021-03192-Z

The authors have supplied new figures to replace the figures in the original publication Figs. 1, 2, 4, 6, 7 and 8 .

The original article can be found online at https://doi.org/10.1007/s10584-021-03192-z

Chen Zhou

chenzhou@nju.edu.cn

$\triangle$ Manchun Li

limanchun@nju.edu.cn

1 School of Geography and Ocean Science, Nanjing University, Nanjing 210023, China

2 Jiangsu Provincial Key Laboratory of Geographic Information Science and Technology, Nanjing University, Nanjing 210023, China 


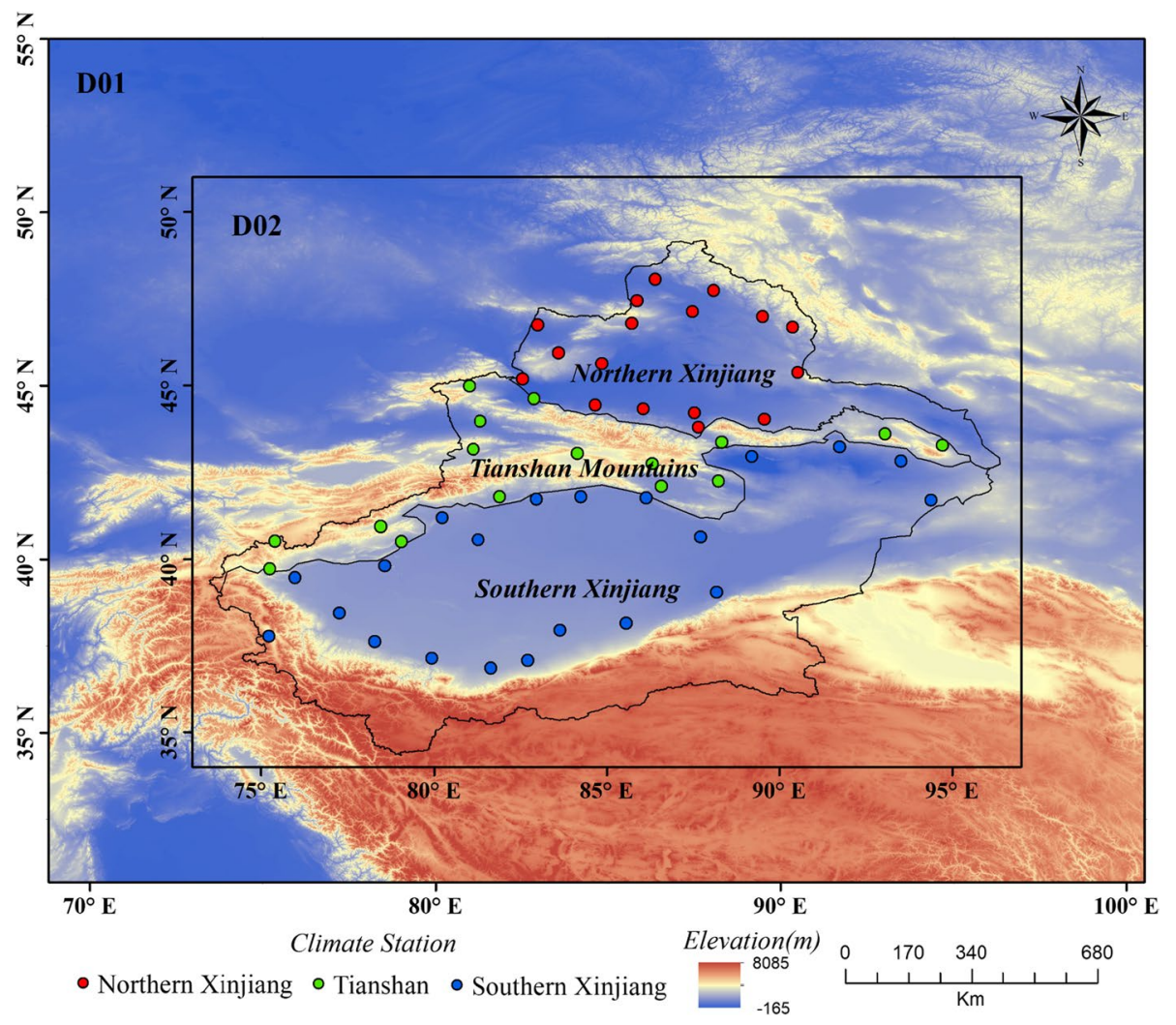

Fig. 1 WRF simulated domains (50 km (D01) and $10 \mathrm{~km}$ (D02)), and the ground meteorological stations with consistent precipitation variations in the study area (D02) 


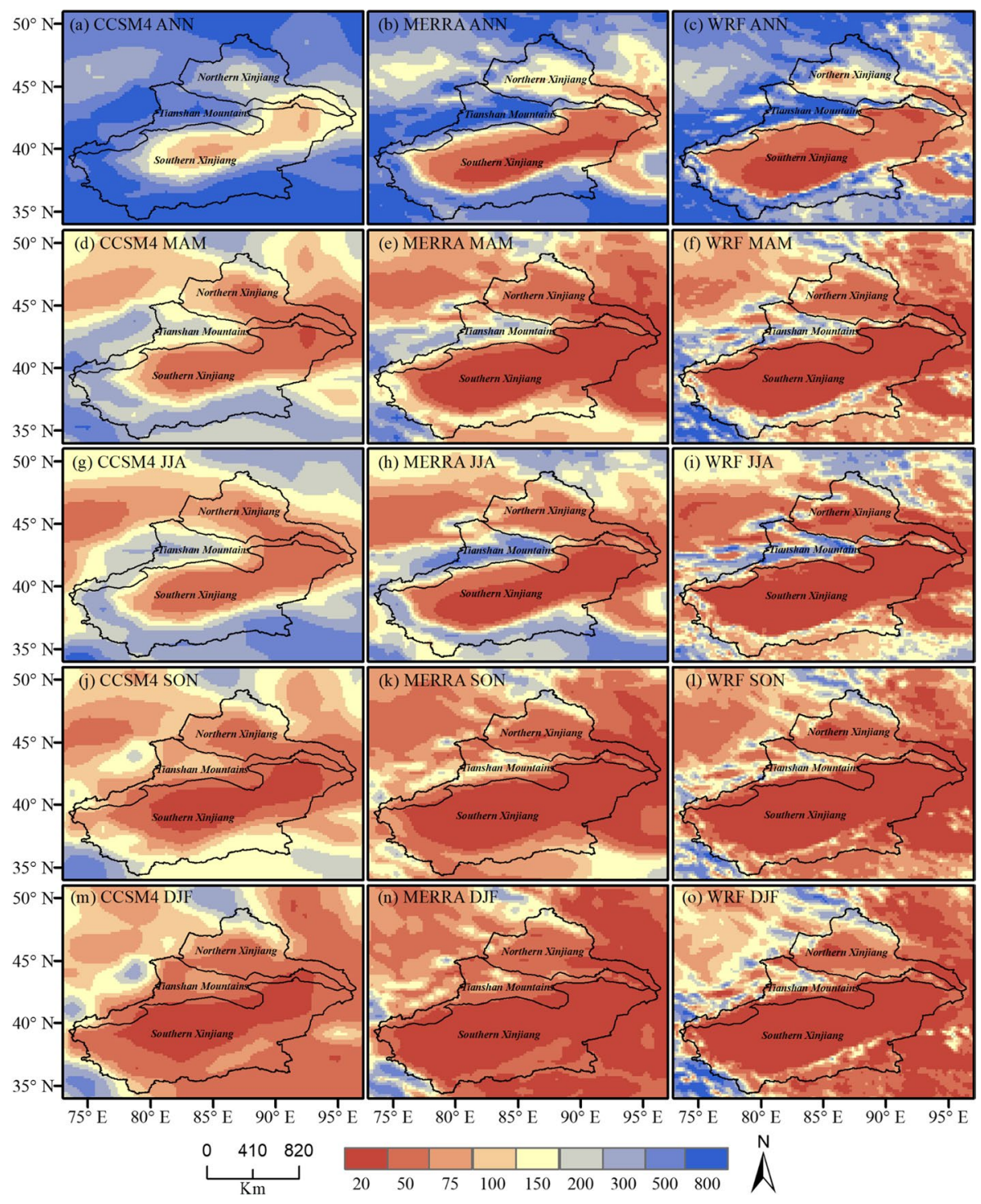

Fig. 2 Mean annual and seasonal spatial patterns of precipitation for 1986-2005 derived from CCSM4 simulation (a, d, g, j, m), MERRA reanalysis data $(\mathbf{b}, \mathbf{e}, \mathbf{h}, \mathbf{k}, \mathrm{n})$, and WRF simulation $(\mathbf{c}, \mathbf{f}, \mathbf{i}, \mathbf{l}, \mathbf{o})$. ANN: annual (a-c), MAM: spring (d-f), JJA: summer (g-i), SON: autumn (j-l), DJF: winter (m-o) 

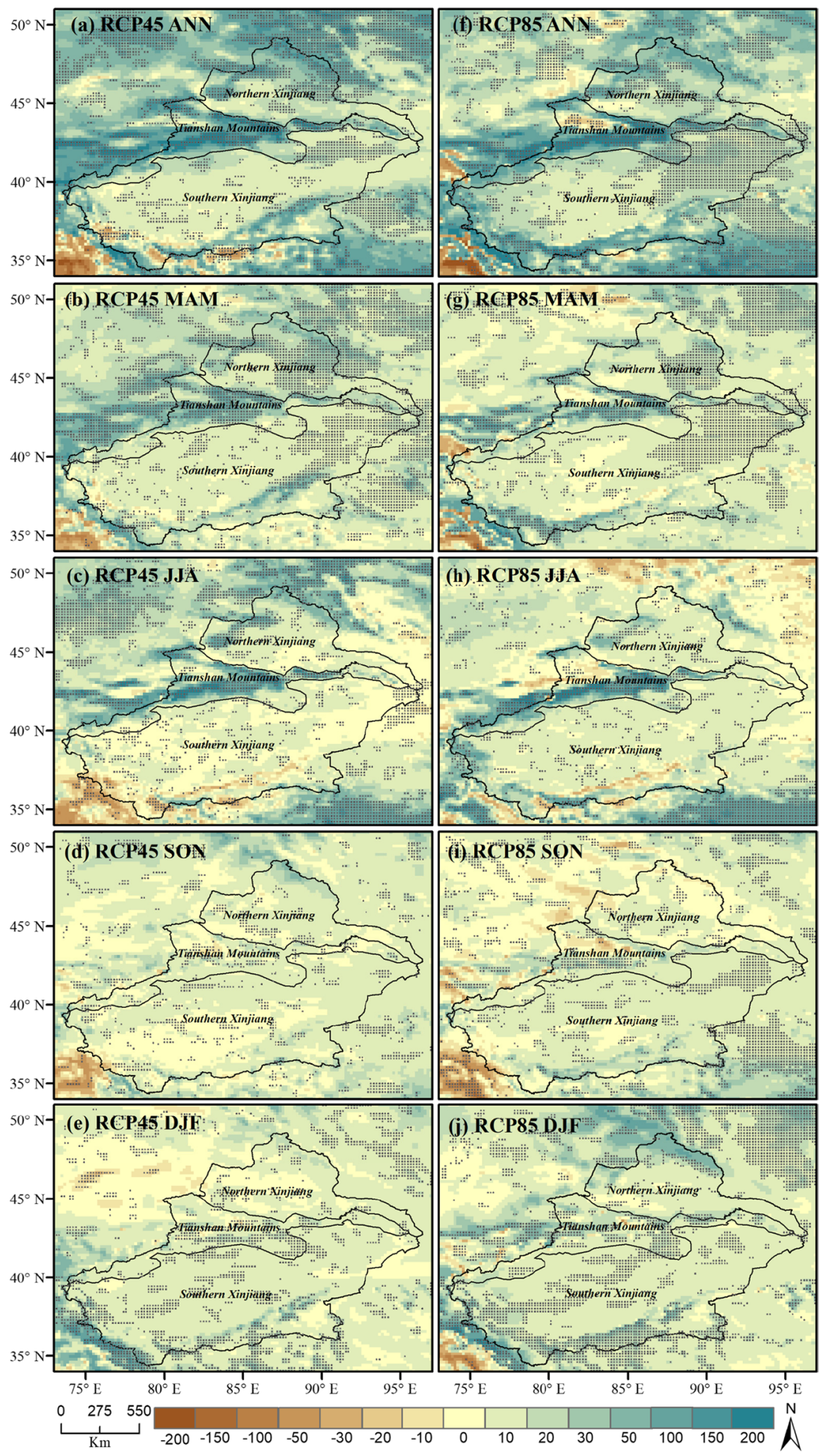
4Fig. 4 Spatial distributions of the near-future difference (2040-2059 relative to 1986-2005) of annual, spring, summer, autumn, and winter precipitations under RCP4.5 (a, b, c, d, and e, respectively) and RCP8.5 (f, $\mathbf{g}, \mathbf{h}, \mathbf{i}$, and $\mathbf{j}$, respectively). The hatched areas indicate that the differences are significant at the $95 \%$ confidence level in a two-tailed Student's $t$-test (units: $\mathrm{mm}$ )
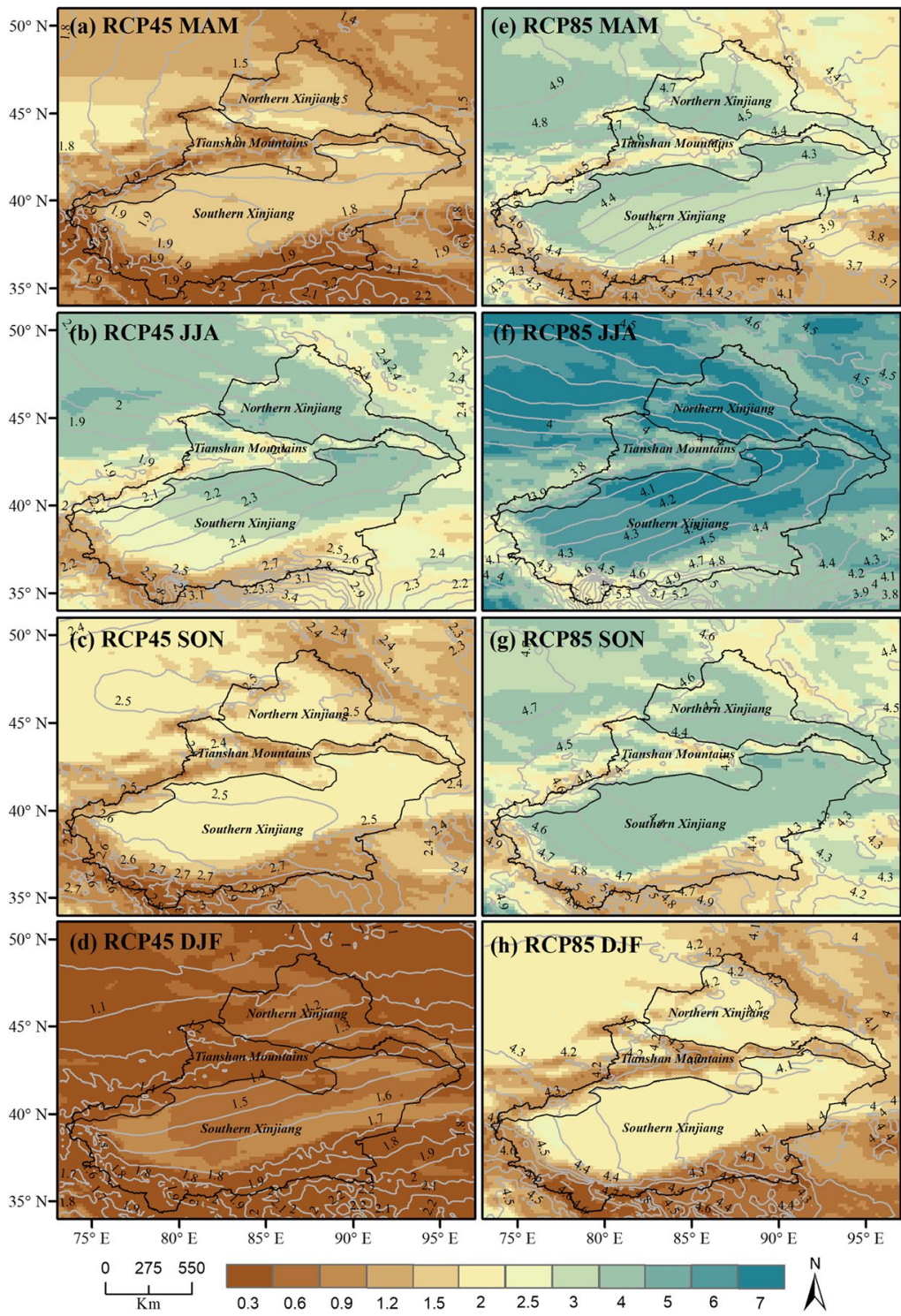

Fig. 6 Differences in PW (color scale, units: $\mathrm{kg} \cdot \mathrm{m}^{-2}$ ) and 500-hPa air temperature (contour line, line interval $0.1 \mathrm{~K}$ ) averaged under RCP4.5 and RCP8.5 in the future relative to the present day 

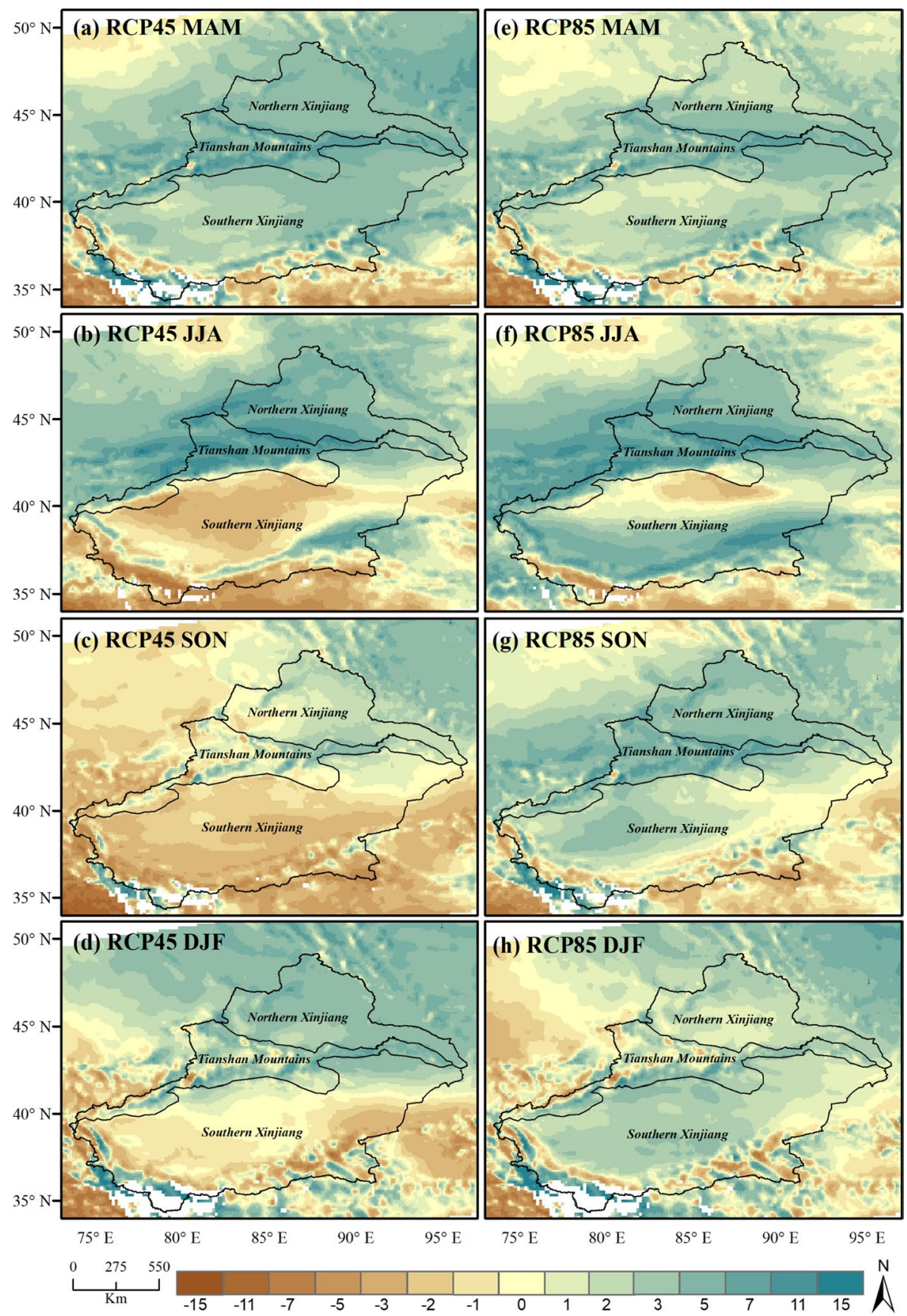

Fig. 7 Differences in 700-hPa RH (units: \%) averaged under RCP4.5 and RCP8.5 in the future relative to the present day 

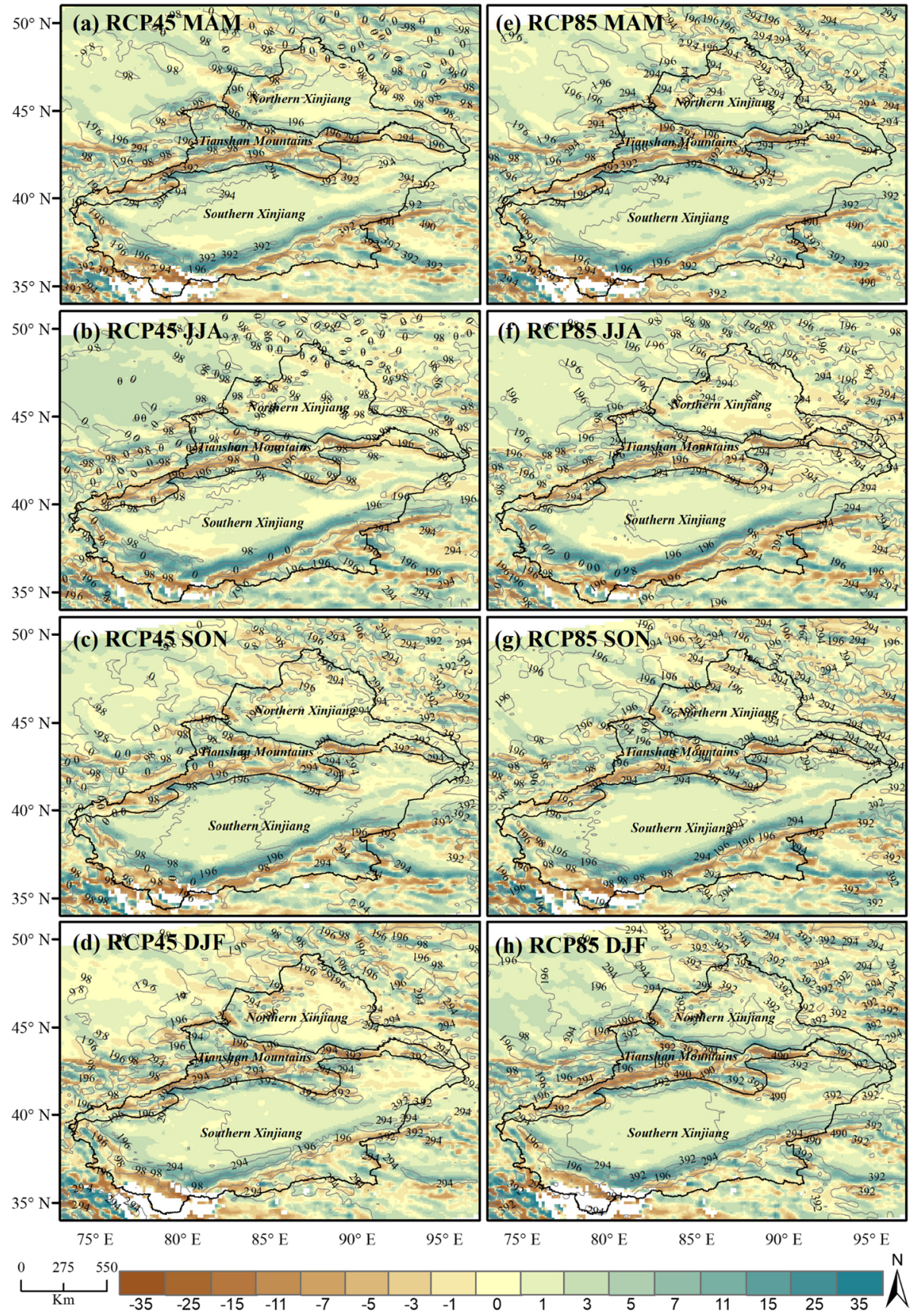

Fig. 8 Differences in relative vorticity (color scale, unit: $10^{-5} \mathrm{~s}^{-1}$ ) and 500-hPa geopotential (contour line, line interval $98 \mathrm{gpm}$ ) averaged under RCP4.5 and RCP8.5 relative to the present day. The white area is underneath the ground

Publisher's note Springer Nature remains neutral with regard to jurisdictional claims in published maps and institutional affiliations. 